\title{
ANALYSIS RISK FACTORS FOR NECK PAIN COMPLAINTS IN PRODUCTION WORKERS AT PT MARUKI INTERNATIONAL INDONESIA
}

\author{
Naurah Nadhifah, Irianto, A.Besse Ahsaniyah \\ Program Studi Fisioterapi, Fakultas Keperawatan, Universitas Hasanuddin, Makassar
}

Correspondence author:

Naurah Nadhifah

Program Studi Fisioterapi, Fakultas Keperawatan, Universitas Hasanuddin, Makassar

Email: naurah22@gmail.com

\section{Article Info:}

Received: 22 May 2019

Revised: 21 June 2019

Accepted: 14 July 2019

Available online: 31 July 2019

Keywords: Neck Pain, Age, Gender, Work Posture, Work

Attitude, Years of Service,

Equality of Shoulder

Height.

DOI: $10.20956 / n m s j . v 4 i 1.6590$

\begin{abstract}
Intorduction: The current most frequent health problem is Musculoskeletal Disorder (MSDs), which is pain in the neck muscles. Neck pain is a complaint taken at the back of the upper spine or cervical. Many factors affect neck pain. This study aims to determine the relationship of each risk factors with neck pain. Methods: This research was a descriptive cross sectional study involving 43 respondents based on the purposive sampling method. Risk factors taken were age, sex, years of service, work attitude, equality of shoulder height, and work posture measurements using Hand Arm Risk-Assesment Method (HARM)) and using the Visual Analog Scale (VAS) to assess the level of neck pain.

Results: : Data analysis using spearman with a value of $p<0.05$ for years of service and work posture and the others factors with a value of $p>0.05$ for sex, age, work attitude and equality of shoulder height that showed there was not significant relationship between gender, age, work attitude and equality of shoulder height with neck pain.

Conclusion: There was a significant relationship between years of service and work posture with neck pain and there was not significant relationship between gender, age, work attitude and equality of shoulder height with neck pain.
\end{abstract}

\section{Pendahuluan}

Kesehatan sangatlah penting bagi setiap individu. Masalah kesehatan saat bekerja yang paling sering muncul adalah Musculoskeletal Disorder (MSDs), yakni keluhan pada bagianbagian otot skeletal yang dirasakan oleh seseorang mulai dari keluhan sangat ringan sampai sangat sakit $^{1}$.

Salah satu keluhan MSDs yang paling sering muncul khususnya pada orang dewasa adalah nyeri pada otot leher. Kondisi ini disebabkan karena beberapa faktor. Nyeri leher adalah masalah umum dengan dua pertiga populasi mengalami nyeri leher pada suatu saat dalam kehidupan ${ }^{2}$. Setiap tahunnya, diperkirakan sekitar $16,6 \%$ populasi dewasa mengeluh rasa tidak enak di leher, bahkan $0,6 \%$ akan berlanjut menjadi nyeri leher yang berat ${ }^{3}$.

PT. Maruki International Indonesia adalah salah satu pabrik penghasil furniture yang terbuat dari kayu dan terdiri dari beberapa pabrik Berdasarkan hasil observasi, di pabrik tersebut ada klinik untuk pekerja yang mengalami masalah kesehatan. Berdasarkan hasil wawancara dengan dokter disana, nyeri leher merupakan MDSs kedua tertinggi di pabrik tersebut. Wawancara dengan pekerja juga dilakukan dan banyak yang mengalami keluhan nyeri leher. Pekerja yang mengalami nyeri leher jika dilihat dari postur kerjanya adalah pekerja yang lebih 
banyak menggunakan leher, tangan, dan bahu dengan gerakan yang sama. Hal ini dapat mengakibatkan suplai oksigen ke otot menurun, proses metabolisme karbohidrat terhambat dan sebagai akibatnya terjadi penimbunan asam laktat yang dapat menimbulkan rasa nyeri otot ${ }^{4}$.

Bekerja dengan kepala menunduk dalam waktu yang lama merupakan faktor risiko terjadinya nyeri leher. Postur bahu yang tidak normal juga mengakibatkan ketidakseimbangan dan kelemahan otot. Hal ini sangat berkaitan dengan pekerja di PT. Maruki, karena pekerja rata-rata melakukan pekerjaan dominan duduk ataupun dominan berdiri. Salah satu postur buruk yang berhubungan dengan leher dan bahu adalah scoliosis. Penyebab Skoliosis bermacam-macam, ada yang bawaan dari lahir. Banyak penelitian yang mengatakan bahwa penyebab skoliosis tidak diketahui penyebab jelasnya namun sebenarnya masyarakat tidak sadar bahwa kebiasaan sehari-hari mereka yang salah itulah yang menyebabkan skoliosis tersebut terbentuk (Skoliosis Idiopatik). Salah satu gejala skoliosis adalah tidak samanya tinggi bahu dan telinga, oleh karena itu skoliosis dapat diukur dengan pengukuran dasar antropometri, yaitu the equality of the shoulder.

Bukan hanya dari faktor lama kerja dan postur, tetapi jenis kelamin juga sangat mempengaruhi keluhan nyeri leher. Perempuan diketahui memiliki prevalensi nyeri leher dan nyeri punggung yang lebih tinggi dan lebih rentan terhadap faktor risiko lingkungan dibandingkan pria 5 .

Dari segi usia, pekerja pabrik di PT Maruki International Indonesia Makassar ratarata berusia $>30$ tahun. Berdasarkan penelitian mengenai "The Prevalence, Risk Factors and Consequences of Neck Pain in Office Employees" menunjukkan bahwa karyawan kantor yang lebih tua lebih mungkin mengalami nyeri leher dibandingkan dengan peserta yang lebih muda. Studi ini menunjukkan bahwa pekerja pada usia di atas 40 tahun dan dengan pengalaman kerja yang tinggi berada pada risiko yang lebih tinggi menderita nyeri leher ${ }^{6}$. Masa kerja yang lama juga sangat mempengaruhi adanya keluhan nyeri, apalagi di PT. Maruki rata-rata pekerjanya telah bekerja di atas 10 tahun bahkan ada yang di atas 20 tahun.

Keluhan nyeri leher seringkali dihiraukan oleh beberapa pekerja, apabila keluhan-keluhan tersebut didiamkan dan terjadi berulang kali dapat menyebabkan cidera dan berakibat fatal ${ }^{7}$. Pekerja di PT. Maruki kurang mengetahui sikap tubuh saAT bekerja yang benar dan bekerja dengan sikap sesuka hatinya sehingga mengalami keluhan nyeri leher. Melakukan pekerjaan dengan sikap yang salah dapat menambah beban kerja otot sehingga terjadi rasa nyeri ${ }^{8}$. Untuk itu diperlukan analisis faktor-faktor risiko dengan mengetahui hubungan masing-masing faktor risiko dengan tingkat keluhan nyeri leher upaya mencegah dan minimalisasi timbulnya risiko di lingkungan kerja.

\section{METODE \\ Lokasi dan rancangan penelitian}

Penelitian ini dilaksanakan di PT Maruki International Indonesia. Lokasi ini dipilih karena pekerja di PT. Maruki bekerja dalam waktu yang lama secara terus menerus dan bekerja dengan postur sesuka hatinya. Penelitian ini yakni penelitian metode deskriptif dengan metode pengambilan sampel purposive sampling.

\section{Populasi dan sampel}

Populasi dalam penelitian ini adalah seluruh pekerja pabrik PT. Maruki International Indonesia yang mengalami keluhan nyeri leher (nyeri di regio posterior tulang servikal, dari superior nuchal line sampai T1 dengan atau tanpa penjalaran ke kepala, badan, dan ekstremitas atas) sesuai dengan diagnosis dari klinik di pabrik tersebut. Sampel dalam penelitian ini berjumlah 43 orang diperoleh dari populasi penelitian yang memenuhi kriteria inklusi yang telah ditetapkan peneliti, meliputi pekerja pabrik, mengalami keluhan nyeri leher, dan bersedia menjadi responden.

\section{Metode pengumpulan data}

Pengumpulan data dilakukan oleh peneliti dengan pedoman wawancara. Informasi tentang karakteristik dan keadaan umum responden, meliputi nama, umur, jenis kelamin, masa kerja, dan sikap kerja ditanyakan secara langsung. Data keluhan nyeri leher, postur, dan equality of shoulder height diperoleh melalui pengukuran langsung kepada pekerja dengan menggunakan alat ukur Visual Analog Scale (VAS) dengan derajat 0 (tidak ada nyeri), 1-3 (nyeri leher ringan), 4-6 (nyeri leher sedang), 7-10 (nyeri leher berat), serta Hand Arm Risk Assesment Method (HARM), dan meteran. 


\section{Analisis data}

Data yang diperoleh diolah menggunakan software SPSS Statistic Data Editor 22 dengan menggunakan Uji spearman untuk melihat hubungan antara masing-masing faktor riisko dengan tingkat keluhan nyeri leher pada pekerja pabrik PT Maruki International Indonesia

\section{Hasil}

Hasil penelitian menunjukkan distribusi karakteristik sampel penelitian dari setiap variable yang diperiksa. Karakteristik sampel penelitian menunjukkan bahwa proporsi responden paling banyak pada jenis kelamin laki-laki sebanyak 31 pekerja (72.1\%) dan wanita sebanyak 12 pekerja (27.9\%). Berdasarkan usia, didapatkan responden dengan usia masa dewasa awal sebanyak 6 pekerja $(14.0 \%)$, masa dewasa akhir 24 pekerja $(55.8 \%)$, masa lansia awal sebanyak 13 pekerja (30.2\%), dan pada masa lansia akhir dan masa manula didapatkan 0 sampel (0\%). Berdasarkan sikap kerja didapatkan responden dengan sikap kerja duduk 21 pekerja (48.8\%) dan sikap kerja berdiri sebanyak 22 pekerja $(51.2 \%)$. Berdasarkan masa kerja didapatkan responden yang bekerja $<6$ tahun sebanyak 1 pekerja (2.3\%), 6-10 tahun sebanyak 7 pekerja (16.3\%), dan yang bekerja $>10$ tahun didapatkan sebanyak 35 pekerja (81.4\%).
Tabel 1. Distribusi Responden Berdasarkan Karakteristik

\begin{tabular}{|c|c|c|}
\hline Karakteristik Responden & Frekuensi & Persentase (\%) \\
\hline \multicolumn{3}{|l|}{ Jenis Kelamin } \\
\hline Pria & 31 & 72.1 \\
\hline Wanita & 12 & 27.9 \\
\hline Total & 43 & 100.0 \\
\hline \multicolumn{3}{|l|}{ Usia } \\
\hline Masa Dewasa Awal & 6 & 14.0 \\
\hline Masa Dewasa Akhir & 24 & 55.8 \\
\hline Masa Lansia Awal & 13 & 30.2 \\
\hline Masa Lansia Akhir & 0 & 0 \\
\hline Masa Manula & 0 & 0 \\
\hline Total & 43 & 100.0 \\
\hline \multicolumn{3}{|l|}{ Sikap Keria } \\
\hline Duduk & 21 & 48.8 \\
\hline Berdiri & 22 & 51.2 \\
\hline Total & 43 & 100.0 \\
\hline \multicolumn{3}{|l|}{ Masa Kerja } \\
\hline$<6$ tahun & 1 & 2.3 \\
\hline 6-10 tahun & 7 & 16.3 \\
\hline$>10$ tahun & 35 & 81.4 \\
\hline Total & 43 & 100.0 \\
\hline \multicolumn{3}{|l|}{$\begin{array}{l}\text { Equality of Shoulder } \\
\text { Height Kanan }\end{array}$} \\
\hline $14-16 \mathrm{~cm}$ & 5 & 11.6 \\
\hline $16.1-18 \mathrm{~cm}$ & 15 & 34.9 \\
\hline $18.1-20 \mathrm{~cm}$ & 19 & 44.2 \\
\hline $20.1-22 \mathrm{~cm}$ & 4 & 9.3 \\
\hline Total & 43 & 100.0 \\
\hline \multicolumn{3}{|l|}{$\begin{array}{c}\text { Equality of Shoulder } \\
\text { Height Kiri }\end{array}$} \\
\hline $14-16 \mathrm{~cm}$ & 7 & 16.3 \\
\hline $16.1-18 \mathrm{~cm}$ & 19 & 44.2 \\
\hline $18.1-20 \mathrm{~cm}$ & 15 & 34.9 \\
\hline $20.1-22 \mathrm{~cm}$ & 2 & 4.7 \\
\hline Total & 43 & 100.0 \\
\hline \multicolumn{3}{|l|}{ Postur Keria } \\
\hline Tidak ada Risiko & 0 & 0 \\
\hline Peningkatan Risiko & 18 & 41.9 \\
\hline Risiko Tinggi & 25 & 58.1 \\
\hline Total & 43 & 100.0 \\
\hline \multicolumn{3}{|l|}{$\begin{array}{c}\text { Tingkat Keluhan Nveri } \\
\text { Leher }\end{array}$} \\
\hline Nyeri Ringan & 2 & 4.7 \\
\hline Nyeri Sedang & 18 & 41.9 \\
\hline Nyeri Berat & 23 & 53.5 \\
\hline Total & 43 & 100.0 \\
\hline
\end{tabular}

Sumber: Data primer, 2019 
Dalam kategori equality of shoulder height, didapatkan equality of shoulder height kanan dengan nilai 14-16 cm sebanyak 5 pekerja (11.6\%), 16.1-18 cm sebanyak 15 pekerja (34.9\%), 18.1-20 cm sebanyak 19 pekerja (44.2\%), dan 20.1-22 cm sebanyak 4 pekerja $(9.3 \%)$. Untuk equality of shoulder height kiri dengan nilai $14-16 \mathrm{~cm}$ sebanyak 7 pekerja (16.3\%), 16.1-18 cm sebanyak 19 pekerja (44.2\%), 18.1-20 cm sebanyak 15 pekerja (34.9\%), dan 20.1-22 cm sebanyak 2 pekerja (4.7\%). Berdasarkan postur kerja, didapatkan tidak ada risiko 0 pekerja $(0 \%)$, didapatkan terjadi peningkatan risiko sebanyak 18 pekerja (41.9\%), dan postur kerja dengan risiko tinggi sebanyak 25 pekerja (58.1\%). Sedangkan berdasarkan tingkat keluhan nyeri leher ditemukan nyeri leher ringan sebanyak 2 pekerja (4.7\%), nyeri leher sedang sebanyak 16 pekerja (41.9\%), dan paling banyak yakni nyeri leher berat sebanyak 23 pekerja (53.5\%).

Tabel 2. Hubungan Jenis Kelamin dengan Tingkat Tingkat Keluhan Nyeri Leher

\begin{tabular}{|c|c|c|c|}
\hline $\begin{array}{l}\text { Sumber } \\
\text { Data }\end{array}$ & $\mathrm{N}$ & $\mathrm{R}$ & $\begin{array}{c}\text { Nilai } \\
\mathrm{P}\end{array}$ \\
\hline Jenis & & & \\
\hline Kelamin & & & \\
\hline $\begin{array}{c}\text { Tingkat } \\
\text { keluhan } \\
\text { nyeri } \\
\text { leher }\end{array}$ & 43 & 0.036 & 0.821 \\
\hline
\end{tabular}

Tabel 3. Hubungan Usia dengan Tingkat Keluhan Nyeri Leher

\begin{tabular}{cccc}
$\begin{array}{c}\text { Sumber } \\
\text { Data }\end{array}$ & $\mathrm{N}$ & $\mathrm{R}$ & $\begin{array}{c}\text { Nilai } \\
\mathrm{P}\end{array}$ \\
\hline $\begin{array}{c}\text { Usia } \\
\text { Tingkat } \\
\text { keluhan } \\
\text { nyeri } \\
\text { leher }\end{array}$ & 43 & -0.070 & 0.658 \\
\hline \multicolumn{5}{c}{ Sumber: Data Primer, 2019}
\end{tabular}

Tabel 4. Hubungan Sikap Kerja dengan Tingkat Keluhan Nyeri Leher

\begin{tabular}{cccc}
\hline $\begin{array}{c}\text { Sumber } \\
\text { Data }\end{array}$ & $\mathrm{N}$ & $\mathrm{R}$ & $\begin{array}{c}\text { Nilai } \\
\mathrm{P}\end{array}$ \\
\hline $\begin{array}{c}\text { Sikap } \\
\text { Kerja }\end{array}$ & & & \\
$\begin{array}{c}\text { Tingkat } \\
\text { keluhan } \\
\text { nyeri }\end{array}$ & 43 & -0.241 & 0.120 \\
leher & & & \\
\hline \multicolumn{5}{c}{ Sumber: Data Primer, 2019 }
\end{tabular}

Tabel 5. Hubungan Masa Kerja dengan Tingkat Keluhan Nyeri Leher

\begin{tabular}{cccc}
\hline $\begin{array}{c}\text { Sumber } \\
\text { Data }\end{array}$ & $\mathrm{N}$ & $\mathrm{R}$ & $\begin{array}{c}\text { Nilai } \\
\mathrm{P}\end{array}$ \\
\hline $\begin{array}{c}\text { Masa } \\
\text { Kerja }\end{array}$ & & & \\
$\begin{array}{c}\text { Tingkat } \\
\text { keluhan } \\
\text { nyeri } \\
\text { leher }\end{array}$ & 43 & 0.349 & 0.022 \\
\hline
\end{tabular}

Sumber: Data Primer, 2019

Tabel 6. Hubungan Equality of Shoulder Height Kanan dan Kiri dengan Tingkat Keluhan Nyeri Leher

\begin{tabular}{|c|c|c|c|}
\hline $\begin{array}{c}\text { Sumber } \\
\text { Data }\end{array}$ & $\mathrm{N}$ & $\mathrm{R}$ & Nilai P \\
\hline $\begin{array}{l}\text { equality of } \\
\text { shoulder } \\
\text { height kiri } \\
\text { Tingkat } \\
\text { keluhan } \\
\text { nyeri leher }\end{array}$ & 43 & -0.050 & 0.752 \\
\hline $\begin{array}{l}\text { Sumber } \\
\text { Data }\end{array}$ & $\mathrm{N}$ & $\mathrm{R}$ & Nilai P \\
\hline $\begin{array}{c}\text { equality of } \\
\text { shoulder } \\
\text { height } \\
\text { kanan } \\
\text { Tingkat } \\
\text { keluhan } \\
\text { nyeri leher }\end{array}$ & 43 & 0.097 & 0.535 \\
\hline
\end{tabular}

Sumber: Data Primer, 2019

Tabel 7. Hubungan Postur Kerja dengan Tingkat Keluhan Nyeri Leher

\begin{tabular}{cccc}
\hline $\begin{array}{c}\text { Sumber } \\
\text { Data }\end{array}$ & $\mathrm{N}$ & $\mathrm{R}$ & $\begin{array}{c}\text { Nilai } \\
\mathrm{P}\end{array}$ \\
\hline $\begin{array}{c}\text { Postur } \\
\text { Kerja }\end{array}$ & & & \\
$\begin{array}{c}\text { Tingkat } \\
\text { keluhan } \\
\text { nyeri } \\
\text { leher }\end{array}$ & 43 & 0.371 & 0.014 \\
\hline \multicolumn{3}{c}{ Sumber: Data Primer, 2019 }
\end{tabular}

Berdasarkan data, diperoleh hasil analisis statistik yang menunjukkan bahwa $p<0.05$ untuk masa kerja dan postur kerja yang menunjukkan bahwa terdapat hubungan yang signifikan antara masa kerja dan postur kerja dengan tingkat keluhan nyeri leher sedangkan dengan nilai $\mathrm{p}>0.05$ untuk jenis kelamin, usia, sikap kerja dan equality of shoulder height yang menunjukkan bahwa tidak terdapat hubungan 
yang signifikan antara jenis kelamin, usia, sikap kerja dan equality of shoulder height dengan tingkat keluhan nyeri leher

\section{PEMBAHASAN}

Berdasarkan hasil penelitian diketahui tidak ada hubungan yang bermakna antara jenis kelamin terhadap tingkat keluhan nyeri leher pada pekerja di PT. Maruki International Indonesia. Penelitian ini sesuai dengan yang dilakukan Yunus (2015) mengenai Hubungan antara Beban Tas Punggung dengan Non Specific Neck Pain pada Mahasiswa PSPD UIN Syarif Hidayatullah Jakarta Tahun 2015, yang membahas hubungan faktor risiko jenis kelamin dengan neck pain dan ditemukan tidak ada hubungan $0.150(\mathrm{p}>0.05)$.

Tidak adanya hubungan yang didapatkan antara jenis kelamin dengan tingkat keluhan nyeri leher ini disebabkan karena responden pria yang didapatkan 2 kali lebih banyak dari responden wanita. Hal ini karena di PT. Maruki International Indonesia dominan pekerjanya adalah pria mengingat pekerjaan industri adalah pekerjaan yang berat sehingga lebih baik dikerjakan oleh pria, bukan hanya hal itu, tetapi mesin kerja di PT. Maruki yang juga lebih cocok digunakan oleh pria, sehingga rata-rata pekerjanya adalah pria.

Berdasarkan hasil penelitian diketahui tidak ada hubungan yang bermakna antara usia terhadap tingkat keluhan nyeri leher pada pekerja di PT. Maruki International Indonesia. Penelitian ini sesuai dengan penelitian yang dilakukan Setyowati dkk (2017) mengenai Hubungan Beban Kerja, Postur dan Durasi Jam Kerja dengan Tingkat Keluhan Nyeri Leher pada Porter di Pelabuhan Penyeberangan Ferry Merak-Banten, yang meneliti usia dengan nyeri leher dan didapatkan $p$-value sebesar $0,524(\mathrm{p}>0,05)$ artinya tidak ada hubungan yang signifikan.

Pada penelitian yang dilakukan, nyeri berat dan sedang paling banyak didapatkan pada usia dengan kategori masa dewasa akhir sesuai dengan teori yang mengatakan bahwa pada umumnya keluhan MSD's mulai dirasakan pada usia 25-65 tahun, dimana keluhan pertama biasa dirasakan pada usia 35 tahun dan akan terus meningkat sesuai bertambahnya usia ${ }^{9}$. Namun sayangnya, pada penelitian ini, dari 5 kategori usia, sampel penelitian hanya didaparkan 3 kategori (masa dewasa awal, masa dewasa akhir, dan masa lansia awal) sehingga sulit menentukan korelasi usia dan tingkat keluhan nyeri leher pada pekerja pabrik di PT. Maruki International Indonesia.
Berdasarkan hasil penelitian diketahui tidak ada hubungan yang bermakna antara sikap kerja terhadap tingkat keluhan nyeri leher pada pekerja di PT. Maruki International Indonesia. Penelitian ini sejalan dengan penelitian yang dilakukan Wiyanto (2011) mengenai Hubungan antara Sikap Kerja dengan Keluhan Muskuloskeletal Leher pada buruh panggul di Kawasan Industri Candi Semarang didapatkan tidak ada hubungan antara sikap kerja dengan nyeri leher yakni $p$-value sebesar $0,653(\mathrm{p}>0,05)$.

Nyeri leher berat lebih banyak ditemukan pada sikap kerja duduk yakni sebanyak 14 pekerja. Hal ini sesuai dengan pendapat beberapa penulis bahwa ada hubungan positif antara mempertahankan posisi duduk selama lebih dari $95 \%$ waktu kerja dan nyeri leher ${ }^{10}$. Sedangkan untuk posisi berdiri paling banyak didapatkan pekerja dengan nyeri sedang bukan pada nyeri berat yakni 12 pekerja, hal ini terjadi karena sikap kerja berdiri lebih membebani regio bawah seperti kaki dan paha sesuai dengan teori yang mengatakan bahwa sikap kerja berdiri membutuhkan pengurangan beban fisiologis tubuh pada periode panjang, utamanya pergerakan darah dan penumpukan cairan tubuh di daerah paha $^{7}$, bukan hanya pada regio leher saja. Juga adanya faktor-faktor lain yang menjadi perancu dalam sikap kerja ini, yakni kebiasaan olahraga dari masing-masing pekerja. Berdasarkan wawancara, pekerja yang memiliki nyeri leher ringan ataupun sedang baik dengan sikap kerja berdiri ataupun duduk biasanya melakukan olahraga seperti futsal di saat libur kerja.

Berdasarkan hasil penelitian diketahui ada hubungan yang bermakna antara masa kerja terhadap tingkat keluhan nyeri leher pada pekerja di PT. Maruki International Indonesia. Penelitian ini sesuai dengan penelitian yang dilakukan Mait dkk (2017) mengenai Hubungan Antara Masa Kerja, Suhu Lingkungan Dan Sikap Kerja Terhadap Keluhan Muskuloskeletal Pada Pekerja Pengupas Kelapa Di Kecamatan Kauditan dan didapatkan nilai $p$ value 0,014 .

Keluhan pada kategori $<6$ tahun hanya ditemukan pada nyeri sedang sebanyak 1 orang. Hal ini disebabkan karena proses adaptasi terhadap pekerjaan, sesuai dengan teori yang mengatakan bahwa masa kerja yang lama dapat berpengaruh terhadap nyeri leher karena merupakan akumulasi pembebanan pada otot leher akibat aktivitas 7 . Adanya hubungan dari masa kerja dan tingkat keluhan nyeri leher terjadi karena terlalu lamanya pekerja bekerja apalagi di PT. Maruki, pekerja bekerja 8 jam sehari selama 
5 kali dalam sepekan. Belum lagi ditambahkan dengan pekerjaan sehari-hari diluarkan pekerjaan di pabrik tersebut.

Berdasarkan hasil penelitian diketahui tidak ada hubungan yang bermakna antara equality of shoulder height kanan maupun kiri terhadap tingkat keluhan nyeri leher pada pekerja di PT. Maruki International Indonesia. Peneliti belum menemukan penelitian yang serupa dengan penelitian yang dilakukan karena masih belum ada yang menggunakan equality of shoulder height sebagai pengukuran scoliosis khusus untuk daerah leher itu sendiri. Tidak adanya hubungan juga disebabkan karena belum adanya interpretasi yang didapatkan dari equality of shoulder height. Pada saat melakukan penelitian, peneliti bisa mengamati secara langsung bahwa semakin tinggi badan pekerja, semakin tinggi pula hasil equality of shoulder height-nya Dan scoliosis sangat jelas dilihat dari observasi jika selisih di antara kedua equality of shoulder height kanan maupun kiri cukup tinggi.

Berdasarkan hasil penelitian diketahui ada hubungan yang bermakna antara postur kerja terhadap tingkat keluhan nyeri leher pada pekerja di PT. Maruki International Indonesia. Penelitian ini sesuai dengan penelitian yang dilakukan Setyowati dkk (2017) mengenai Hubungan Beban Kerja, Postur dan Durasi Jam Kerja dengan Tingkat Keluhan Nyeri Leher pada Porter di Pelabuhan Penyeberangan Ferry Merak-Banten, yakni didapatkan $p$-value sebesar $0,018(\mathrm{p}<0,05)$ artinya ada hubungan yang signifikan antara postur dan tingkat keluhan nyeri leher.

Postur kerja yang salah saat bekerja menunjukkan bukti yang kuat sebagai faktor yang dapat berkontribusi terhadap adanya keluhan Musculoskeletal Disorders (MSDs) ${ }^{11}$. Pada penelitian ini sangat jelas bahwa postur berhubungan dengan nyeri leher karena nyeri leher berat didapatkan paling banyak pada postur dengan risiko tinggi sebanyak 17 pekerja dan tidak ada pekerja yang mengalami postur kerja yang tidak berisiko. Hal ini membuktikan bahwa postur kerja di PT. Maruki rata-rata berisiko tinggi dikarenakan waktu kerja yang lama dan masa kerja yang rata-rata $>10$ tahun. Kedua hal tersebut apabila dibarengi dengan postur kerja yang tidak sesuai dan terjadi berulang kali dalam 1 menit dapat meningkatkan risiko nyeri leher.

\section{KESIMPULAN DAN SARAN}

Peneliti menyimpulkan bahwa terdapat hubungan signifikan antara masa kerja dan postur kerja dengan tingkat keluhan nyeri leher dan tidak terdapat hubungan signifikan antara usia, jenis kelamin, sikap kerja, dan equality of shoulder height pada pekerja pabrik PT Maruki Intenational Indonesia. Penelitian ini diharapkan menjadi bahan pertimbangan bagi tenaga kesehatan dalam upaya promotif dan preventif terjadinya nyeri leher pada saat bekerja. Hasil penelitian ini juga diharapkan dapat menjadi bahan masukan dan kajian bagi perusahaan dalam meningkatkan kesehatan pekerjanya dan untuk meningkatkan produktifitas kerja.

\section{DAFTAR PUSTAKA}

1. Hanifah, F. A., Ekawati, Jayanti, S., \& Setyaningsih, Y. (2017). Analisis Tingkat Risiko Ergonomi Menggunakan Metode REBA terhadap Keluhan MSDs pada Pengrajin Batik di Nisya Batik, Kuningan. Jurnal Kesehatan Masyarakat, 5(April), 106-113.

2. Khatun, M. H. (2015). Proportion of Neck Pain and Its Associated Risk Factors among Office Workers in Dhaka City. Europeam Academic Reseacrh, II(11), 14514-14523.

3. Widyadharma, I. P. E., \& Purwata, T. E. (2017). Nyeri Miofasial Servikal.

4. Winihastuti, H. (2016). Hubungan Faktor Risiko Ergonomi dan Keluhan Cumulative Trauma Disorders pada Dokter Gigi di PT . X Tahun 2014. Jurnal Administrasi Rumah Sakit, 3(1), 53-65.

5. Briggs, A. M., Straker, L. M., Burnett, A. F., \& Wark, J. D. (2012). Chronic Low Back Pain is Associated with Reduced Vertebral Bone Mineral Measures in Community-Dwelling Adults. $B M C$ Musculoskeletal Disorders, 13(1), 49.

6. Ehsani, F., Mosallanezhad, Z., \& Vahedi, G. (2017). The Prevalence, Risk Factors and Consequences of Neck Pain in Office Employees. Middle East $J$ Rehabil Health, 4(2).

7. Awal, G. S. D. (2015). Hubungan Sikap Kerja Duduk dengan Keluhan Nyeri Leher pada Pekerja Menggunakan Rapid Upper Limb Asessment (RULA) di PT Tunas Alfin Tbk. 
8. Belayana, I. B. G. B., Darmadi, I. G. W., \& Mahayana, I. M. B. (2014). Hubungan Faktor Waktu Kerja, Waktu Istirahat dan Sikap Kerja terhadap Keluhan Nyeri Tengkuk pada Pengerajin Ukiran Kayu. Jurusan Kesehatan Lingkungan Poltekkes Denpasar, 4.

9. Setyowati, Widjasena, B., \& Jayanti, S. (2017). Hubungan Beban Kerja, Postur dan Durasi Jam Kerja dengan Keluhan Nyeri Leher pada Porter di Pelabuhan Penyeberangan Ferry Merak-Banten. Jurnal Kesehatan Masyarakat (eJournal), 5, 356-368.
10. Machado-Matos, M., \& Arezes, P. M. (2016). Impact of a Workplace Exercise Program on Neck and Shoulder Segments in Office Workers. Dyna, 83(196), 63-68.

11. Mahardika, T., \& Pujotomo, D. (2014). Perancangan Fasitilas Kerja untuk Mengurangi Keluhan Musculoskeletal Disorders (Msds) dengan Metode Rappid Entire Body Assesment pada Pekerja Pembuatan Paving Dan Batako pada Ukm Usaha Baru. Jurnal J@TI UNDIP, 9(2), 109-116. https://doi.org/postur kerja; musculosk eletal disorders ; Rapid Entire Body Assesment; fasilitas kerja 